\title{
Acetylcholine Receptor-Reactive T and B Cells in Myasthenia Gravis and Controls
}

\author{
Hans Link," Ove Olsson, " Jiabin Sun," Wei-Zhi Wang,* Gudrun Andersson," Hans-Peter Ekre,* \\ Talma Brenner," Oded Abramsky," and Tomas Olsson* \\ ${ }^{*}$ Department of Neurology, Karolinska Institutet, Huddinge University Hospital, Stockholm; ${ }^{\ddagger}$ Department of Research \\ and Development Immunobiology, KABI Biopharma, Stockholm, Sweden; and Department of Neurology, \\ Hadassah-Hebrew University Hospital, Jerusalem, Israel
}

\begin{abstract}
Myasthenia gravis (MG) is strongly associated with antibodies to acetylcholine receptor (AChR), whereas the extent of $\mathbf{T}$ cell involvement is not settled. The number of cells secreting interferon-gamma (IFN- $\gamma$ ) in response to AChR during $48 \mathrm{~h}$ culture of blood mononuclear cells (PBL) may reflect AChR-reactive $T$ cells. Using an immunospot assay, we detected such cells in 23 of 30 patients with MG at a mean number of 1 per 33.333 PBL. AChR-reactive $T$ cells were also found in patients with other neurological diseases (OND) and in healthy subjects but at lower frequencies and numbers. The $T$ cell response to purified protein derivative and to PHA, and also to two major myelin proteins (basic protein and proteolipid protein) did not differ between MG and the two control groups, underlining the specificity of an augmented T cell reactivity to $A C h R$ in MG. Evaluation of the $B$ cell response by enumerating anti-AChR IgG antibody secreting cells revealed such cells in 27 of 28 patients with MG at a mean value of 1 per 14,085 PBL. Cells secreting anti-AChR antibodies of the IgA and IgM isotypes were also detected in MG, but less frequently, at lower numbers, and only in conjunction with IgG antibody secreting cells. Anti-AChR antibody secreting cells were also found among patient with OND and in healthy controls, but at lower frequencies and numbers. These data confirm that $\mathrm{AChR}$ is a major target for autoimmune response in MG. (J. Clin. Invest. 1991. 87:21912196.) Key words: myasthenia gravis • autoreactive $T$ cells • acetylcholine receptor $\bullet$ antibodies $\bullet$ autoimmunity
\end{abstract}

\section{Introduction}

Myasthenia gravis (MG) ${ }^{1}$ can be considered a prototype for autoimmune disease in the human. Antibodies against the nicotinic acetylcholine receptor (AChR) of the neuromuscular junction are detectable in $\sim 85 \%$ of the patients with MG (1, 2). Further evidence for the importance of anti-AChR antibod-

Address reprint requests to Dr. H. Link, Department of Neurology, Karolinska Institutet, Huddinge University Hospital, S-141 86 Huddinge, Stockholm, Sweden.

Received for publication 17 September 1990 and in revised form 29 January 1991.

1. Abbreviations used in this paper: $\mathrm{AChR}$, acetylcholine receptor; IFN$\gamma$, interferon-gamma; MBP, myelin basic protein; MG, myasthenia gravis; OND, other neurological diseases; PBL, blood mononuclear cell culture; PLP, proteolipid protein; PPD, purified protein derivative.

J. Clin. Invest.

(c) The American Society for Clinical Investigation, Inc. 0021-9738/91/06/2191/06 \$2.00

Volume 87, June 1991, 2191-2196 ies in the pathogenesis of MG include demonstration of passive transfer of MG by IgG from patients with MG to mice (3), transient presence of antibodies and muscular weakness in some of the infants of mothers with MG, and beneficial effect of plasmapheresis. The anti-AChR antibodies are assumed to induce the destruction of the AChR, characteristic for MG, thereby causing the abnormal muscular fatigue and other manifestations of MG (4). The AChRs are pentameric structures consisting of $\alpha_{2}, \beta$, gamma, and $\delta$ subunits (5). Tzartos et al. have shown that $\sim 60 \%$ of anti-AChR antibodies found in MG patients' sera are directed to conformational determinants of the two $\alpha$-subunits which are known as the main immunogenic region (MIR) and localized on the extracellular portion of the AChR (6). The concept of a MIR of the AChR as the principal stimulus for antibody production in MG has been challenged by others (7).

The extent of $\mathrm{T}$ cell involvement in MG is less well defined. When testing reactivity to $\mathrm{AChR}$ by the $\mathrm{T}$ cell proliferation assay employing $\left[{ }^{3} \mathrm{H}\right]$ thymidin incorporation, Newsom-Davis and his group have demonstrated a positive response only among $17 \%$ of patients with MG, and also in $9 \%$ of the control patients (8). AChR-reactive T cell lines have been raised from patients with MG (9), and evidence has been presented that such cell lines recognize predominantly the $\alpha$-subunits among the multiple AChR epitopes $(10,11)$, in analogy with the B cell response. In their analysis of $T$ cell proliferative responses to synthetic peptides of the human AChR $\alpha$-chain sequence, Harcourt et al. observed specific responses to peptide 125-143 in $26 \%$ of MG patients, but also in $40 \%$ of controls including healthy subjects (12). The authors speculate whether $\mathrm{T}$ cell reactivity to AChR may be more widespread than previously suspected, and that such clones may be controlled more effectively in healthy subjects than in MG, or that T cell-reactive peptides 125-143 may not inevitably be pathogenic in humans. Interestingly, however, a section of this peptide 125-143 can induce experimental autoimmune MG in rats (13).

We have in this study adopted assays to evaluate the $T$ and B cell responses to AChR at the level of single cells. After recognition of relevant antigen on presenting cells, "memory" $T$ cells respond by secretion of cytokines, among them interferon-gamma (IFN- $\gamma$ ) (14). This phenomenon can be utilized to enumerate specific "memory" $T$ cells among isolated mononuclear cells $(15,16)$. For the B cell-plasma cell axis, individual cells secreting specific antibodies of different isotypes can be detected and enumerated in vitro $(17,18)$. We have applied these principles to the analysis of mononuclear cells from peripheral blood from patients with MG and controls. We now report that most patients with MG have AChR-reactive T cells and anti-AChR antibody secreting cells in peripheral blood. AChR-specific T and B cells may, however, also occur in other neurological diseases and in healthy subjects but less frequently and at lower numbers compared to MG. 


\section{Methods}

Patients. 30 patients (22 females) had MG. Their age was 33-78 yr (mean, 54). The diagnosis was based on the clinical signs and symptoms, previous laboratory tests including serum antibodies to AChR and single fiber EMG abnormalities, and effects of generally used treatments. 16 of the patients had been thymectomized. The mean interval between onset of symptoms of MG and present study was 11 yr (0.537). Immunosuppressive drugs were administered to seven of the patients at the time of sampling. Two patients had other autoimmune diseases in parallel; one had Sjögren syndrome and one had type I diabetes mellitus.

44 patients ( 26 females) had other neurological diseases. Their age was 22-79 yr (mean, 55). 10 of the patients had acute aseptic meningoencephalitis, 8 had cerebrovascular disease, 6 had rhizopathy, 4 pain syndrome, 4 paresthesia, 2 each had vestibular vertigo, dementia or epilepsy, and 1 each had mononeuropathy, temporal arteritis, spondylotic myelopathy, headache, head trauma, or Parkinson's disease.

32 subjects ( 21 females) comprised of healthy collaborators from the hospital staff. Their age was 24-67 yr (mean, 37).

Antigens. Preparation of torpedo AChR: Torpedo AChR was purified from frozen electric organs of Torpedo californica (Pacific BioMarine, CA) as described (19). Briefly, the receptor was isolated by solubilization of membrane fragments in $1 \%$ Triton X-100, followed by affinity chromatography on a Naja Naja Siamnesis neurotoxin-Sepharose resin. The bound receptor was eluted with carbamycholine followed by dialysis. The specific activity was 3,000-4,500 pmol $\alpha$-Bgt binding sites per milligram protein. The final protein concentration of the AChR preparation was $5 \mu \mathrm{g} / \mathrm{ml}$ in the $\mathrm{T}$ cell assay and $1 \mu \mathrm{g} / \mathrm{ml}$ in the $B$ cell assay.

Control antigens consisted of myelin basic protein (MBP) and proteolipid protein (PLP) prepared from bovine brain $(20,21)$. The MBP preparation gave one single band of $\sim 20 \mathrm{kD}$ when examined by SDS electrophoresis. The PLP preparation was free from any MBP contamination when checked by Western blot employing a rat polyclonal antiserum against MBP. Purified protein derivate (PPD) (Statens Serum Institute, Copenhagen, Denmark) and PHA (Difco, Detroit, MI) were used as controls in the $\mathrm{T}$ cell assay.

Preparation of mononuclear cells. Peripheral blood was taken into heparinized tubes, and mononuclear cells (PBL) were immediately separated by density gradient centrifugation on Ficoll (Lymphoprep; Nyegaard, Oslo, Norway), washed three times in PBS, pH 7.4, and diluted in tissue culture medium consisting of Iscove's modification of Dulbecco's medium (Flow Laboratories, Inc., Irvine, UK) with 2 mmol L-glutamine (Flow Laboratories, Inc.), 5\% (vol/vol) FCS (Gibco, Paisley, UK) and antibiotics. The PBL were adjusted to $10^{6}$ cells per ml in PBS.

Enumeration of AChR-reactive $T$ cells. We utilized the principle of counting activated $\mathrm{T}$ cells secreting IFN- $\gamma$ in presence of relevant antigen (22). The procedure is summarized in Fig. 1. Wells of microtiter plates with 96 wells and nitrocellulose bottoms (Millititre-HA; Millipore Co., Bedford, MA) were coated with 100- $\mu$ l aliquots of the mouse monoclonal anti-human IFN- $\gamma$ antibody 7-B6-5 (23) at $6 \mu \mathrm{g} / \mathrm{ml}$ and $4^{\circ} \mathrm{C}$ overnight, and then washed with PBS. 200- $\mu$ l aliquots containing 2 $\times 10^{5} \mathrm{PBL}$ were added per well. Antigen or lectins were added in $10-\mu 1$ aliquots to a final concentration of $10 \mu \mathrm{g} / \mathrm{ml}$. For each specimen, cells were also applied into wells in which no antigen or lectin was added. PPD was used as positive control antigen. After $48 \mathrm{~h}$ of culture at $37^{\circ} \mathrm{C}$ and $7 \% \mathrm{CO}_{2}$ in humidity, the plates were washed with PBS. $100-\mu 1$ aliquots of a rabbit polyclonal anti-human IFN- $\gamma$ antiserum (Interferon Sciences, New Brunswick, NJ) diluted 1/500 were added to each well for $4 \mathrm{~h}$ at room temperature. After washing, biotinylated anti-rabbit IgG (Vector Laboratories, Inc., Burlingame, CA) diluted 1/1,000 was added for $2 \mathrm{~h}$ at room temperature, followed by avidin-biotin peroxidase complex (ABC Vectastain-Elite Kit; Vector Laboratories, Inc.) diluted $1 / 200$ for $1 \mathrm{~h}$ at room temperature. After peroxidase staining (24), spots corresponding to cells that had secreted IFN- $\gamma$ were enumerated in a dissection microscope. Numbers of spots from cultures

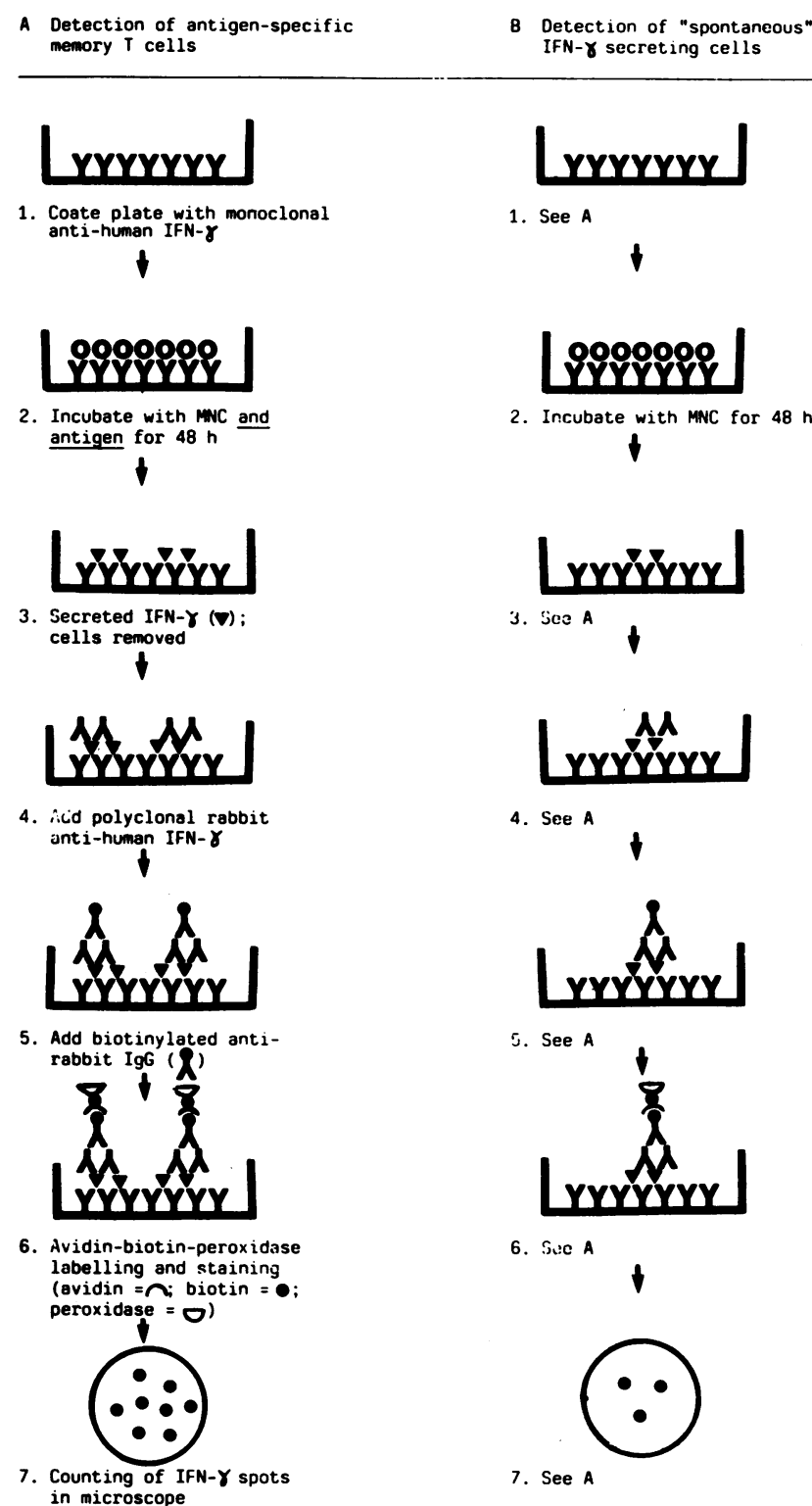

Figure 1. Scheme of immunospot method for detection of antigen-specific memory $\mathrm{T}$ cells $(A)$ and cells secreting IFN- $\gamma$ in absence of antigen or lectin $(B)$.

with no antigen or lectin added (spontaneous IFN- $\gamma$ secreting cells) were counted and subtracted from the values for cultures exposed to antigen or lectin. The results thus obtained are considered to reflect antigen-specific or lectin-reactive $T$ cells. The data are expressed as numbers of spots per $10^{5}$ mononuclear cells. No spots appeared in specificity control experiments in which the capture antibody was exchanged to an irrelevant mouse monoclonal antibody, or the rabbit polyclonal antibody was omitted.

Enumeration of anti-AChR antibody secreting cells and immunoglobulin-secreting cells. A solid-phase enzyme-linked immunospot assay was used, employing microtiter plates with nitrocellulose bottoms as previously described (25). The wells were coated with $100 \mu \mathrm{l}$ per well of AChR diluted in PBS to $1 \mu \mathrm{g} / \mathrm{ml}$ for enumeration of antibody secreting cells, or affinity purified goat anti-human IgG, IgA, and IgM heavy chain-specific antiserum (Sigma Chemical Co., St. Louis, MO) for parallel enumeration of IgG-, IgA-, and IgM-secreting cells. Optimal antigen or antibody concentrations in coating solutions were defined in 
preliminary experiments. After the wells had been coated overnight at $4^{\circ} \mathrm{C}$, the supernatant was removed by suction through the nitrocellulose membranes. The wells were then washed and $100-\mu l$ portions containing $10^{5} \mathrm{PBL}$ were added to individual wells. After incubation overnight at $37^{\circ} \mathrm{C}$ in $7 \% \mathrm{CO}_{2}$ and humidified atmosphere, the wells were emptied, washed, and $100 \mu$ lof diluted high-affinity purified biotinylated goat anti-human IgG, IgA, or IgM antiserum (Sigma Chemical Co.) was added to appropriate wells. Washing, incubation with avidinbiotin peroxidase complex, staining, and counting of immunospots followed as described above. Values obtained were standardized to numbers of spots per $10^{5}$ cultured cells. Variation of quadruplicate cultures was regularly $<10 \%$. We have previously presented evidence that the spots which we detect in this system represent cells secreting antibodies (26).

Statistics. Mann-Whitney's U-test and Spearman's rank correlation test were used for statistical evaluation.

\section{Results}

Autoreactive T cells. After culture of blood mononuclear cells for $48 \mathrm{~h}$ and immunoenzyme staining for secreted IFN- $\gamma$, redbrown immunospots appeared which were easy to count in a dissection microscope. The number of primed $T$ cells responding specifically to an antigen was estimated after subtraction of the value obtained in parallel culture without antigen (Fig. 2).

AChR-reactive $\mathrm{T}$ cells determined by secretion of IFN- $\gamma$ in the presence of $\mathrm{AChR}$, were detected in 23 of the 30 patients with MG (77\%) (Table I; Fig. 2). The numbers of AChR-reactive $T$ cells in the 23 positive patients varied between 1 per 8,333 and 1 per 200,000 PBL (mean, 1 per 33,300 PBL for all 30 patients). AChR-reactive $\mathrm{T}$ cells were found in the two control groups, but at lower numbers $(P<0.05$ and $P<0.001$, respectively; cf. Table I). The diagnoses in the eight OND patients with AChR-reactive $T$ cells were cerebrovascular disease in four patients and Parkinson's disease, head trauma, paresthesia, and rhizopathy in one patient each.

To evaluate the specificity of the $\mathrm{T}$ cell response in MG, we selected as control antigens PPD and the myelin components MBP and PLP. T cell reactivity to PPD was found at similar frequencies and levels in blood from patients with $M G$ and the two control groups (Table I). A proportion of the MG patients had also autoreactive T cells to MBP and to PLP, but the fre-

Table I. Numbers of Antigen (AChR, MBP, PLP, PPD) or Lectin (PHA)-induced Interferon- $\gamma$ Secreting Cells per $10^{5}$ Mononuclear Cells from Peripheral Blood from Patients with MG, OND, and Healthy Controls

\begin{tabular}{llllll}
\hline \multicolumn{1}{c}{ Patients } & \multicolumn{1}{c}{ AChR } & \multicolumn{1}{c}{ MBP } & \multicolumn{1}{c}{ PLP } & \multicolumn{1}{c}{ PHA } & PPD \\
\hline $\begin{array}{l}\text { MG }(n=30) \\
\quad \text { Range }\end{array}$ & $0-12$ & $0-8.5$ & $0-18$ & $5-292$ & $2-250$ \\
$\quad \begin{array}{l}\text { Mean (SD) } \\
P \text { value }\end{array}$ & $3.0(3.4)$ & $0.9(2.2)$ & $1.7(4.3)$ & $82(92)$ & $29(52)$ \\
& $0.05 / 0.001$ & NS/NS & NS/NS & NS/NS & NS/NS \\
$\begin{array}{l}\text { OND }(n=44) \\
\text { Range }\end{array}$ & $0-9.5$ & $0-35$ & $0-13$ & $5-410$ & $0-150$ \\
Mean (SD) & $0.6(1.9)$ & $2.5(6.8)$ & $1.2(2.7)$ & $109(111)$ & $38(38)$ \\
Healthy ( $n=30)$ & & & & & \\
$\quad$ Range & $0-0.5$ & $0-15$ & $0-8.5$ & $5-27$ & $0-196$ \\
Mean (SD) & $0.02(0.09)$ & $1.3(3.5)$ & $1.0(2.1)$ & $93(69)$ & $39(48)$ \\
& & & & &
\end{tabular}

$P$ values refer to difference between MG and OND, and MG and healthy controls, respectively.
Table II. Numbers of Cells Secreting Anti-AChR Antibodies of IgG, IgA, and IgM Isotypes, per $10^{5}$ Mononuclear Cells from Peripheral Blood from Patients with $M G, O N D$, and Healthy Controls

\begin{tabular}{lllll}
\hline \multirow{2}{*}{ Patients } & & \multicolumn{3}{c}{ Anti-AChR antibody secreting cells } \\
\cline { 3 - 5 } & & \multicolumn{1}{c}{ IgG } & \multicolumn{1}{c}{ IgA } & \multicolumn{1}{c}{ IgM } \\
\hline \multirow{2}{*}{ MG } & Range & $0-28$ & $0-9$ & $0-5$ \\
& Mean (SD) & $7.1(6.6)$ & $2.2(2.6)$ & $0.8(1.3)$ \\
& No exam & 28 & 28 & 27 \\
& $P$ value & $0.001 / 0.05$ & $0.01 / 0.05$ & $0.5 / \mathrm{NS}$ \\
OND & Range & $0-10$ & $0-2$ & $0-1$ \\
& Mean (SD) & $1.5(2.5)$ & $0.8(0.8)$ & $0.2(0.4)$ \\
& No exam & 24 & 12 & 13 \\
Healthy & Range & $0-20$ & $0-4$ & $0-2$ \\
& Mean (SD) & $2.8(2.1)$ & $0.6(1.4)$ & $0.5(0.7)$ \\
& No exam & 20 & 8 & 11 \\
& & & & \\
\hline
\end{tabular}

$P$ values refer to difference between MG and OND, and MG and healthy controls, respectively.

quencies did not differ from those in the two control groups, nor did the mean values (Table I).

PHA which promotes polyclonal T cell activation and concurrent IFN- $\gamma$ production, induced similar frequencies and mean numbers of IFN- $\gamma$ secreting cells in MG compared with the two control groups (Table I).

Anti-AChR antibody secreting cells. Cells secreting antiAChR IgG antibodies were detected in peripheral blood from 27 of the $28 \mathrm{MG}$ patients examined (Table II; Fig. 3). The range of antibody secreting cells in the 27 positive patients varied between 1 per 3,571 and 1 per $10^{5}$ blood mononuclear cells (mean, 1 per 14,085 cells for all 28 examined patients).

Cells secreting anti-AChR antibodies of the IgA and the IgM isotypes were also found in blood from the patients with MG, but less frequently, at lower numbers (Fig. 3; Table II), and only in parallel with cells secreting anti-AChR antibodies of the IgG isotype. The mean value for anti-AChR IgA antibody secreting cells was 1 per 45,455 PBL, and for cells secreting corresponding IgM antibodies 1 per 125,000 PBL. Seven of the 27 MG patients evaluated (26\%) had cells secreting anti-

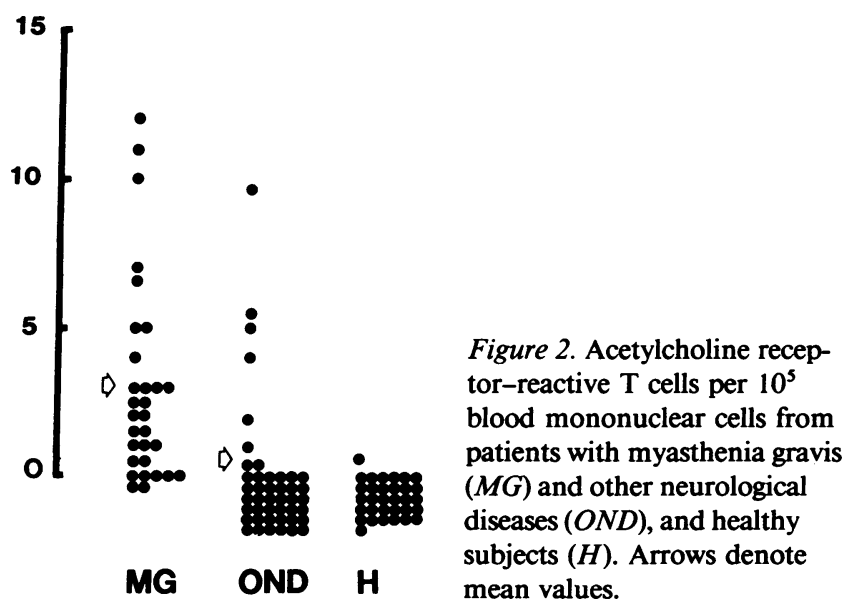


AChR antibodies of all three isotypes, $10(37 \%) \mathrm{had}$ IgG and IgA, $3(11 \%)$ had IgG and IgM, $6(22 \%)$ had IgG only, and in 1 patient no anti-AChR antibody secreting cells were detectable. One patient was examined for IgG and IgA only, and had both cell types.

Anti-AChR antibody secreting cells were not specific for MG. Cells secreting IgG antibodies were found in half of the patients with OND and also in about half of the healthy controls examined. Compared with MG, the numbers were lower in the other neurological disease (OND) patient group (mean, 1 per 66,667 PBL; $P<0.001$ ) and in the healthy controls (mean, 1 per 35,714 PBL; $P<0.05$ ). Similarly, the numbers of antiAChR IgA antibody secreting cells were higher in MG than in OND $(P<0.01)$ and healthy subjects $(P<0.05)$, and the numbers of IgM antibody secreting cells were higher in MG than OND $(P<0.05)$, whereas the difference with healthy controls did not reach significance.

We found a positive correlation $(r=0.56 ; P<0.001)$ between numbers of anti-AChR IgG antibody secreting cells and AChR-reactive T cells in the $28 \mathrm{MG}$ patients. Also in the controls, there was a similar correlation between these two variables.

$T$ and $B$ cell responses to $A C h R$ in thymectomized patients. Of the $30 \mathrm{MG}$ patients, 16 had been subjected to thymectomy (Table III). The mean value of AChR-reactive T cells was higher in the thymectomized group $(P<0.05)$. Numbers of anti-AChR antibody secreting cells of all three isotypes were also higher in the thymectomized patients.

Immunoglobulin secreting cells. The patients with MG had higher numbers of cells secreting IgG in peripheral blood compared with those with OND $(P<0.05)$ or the healthy subjects $(P<0.001)$. For numbers of IgA and IgM secreting cells, no differences were registered between the group (Table IV).

\section{Discussion}

We have presented evidence that a majority of patients with MG have AChR-reactive T cells in peripheral blood. The high numbers of AChR-reactive T cells in MG patients did not reflect a generally increased capacity to produce IFN- $\gamma$ in response to antigen or lectin in MG, because the numbers of $T$ cells responding to the common antigen PPD and to the mitogen PHA did not differ significantly in MG compared with OND or healthy subjects.

Table III. AChR-specific T and B cells in Peripheral Blood from Patients with MG with (Group I) and without Thymectomy (Group II)

\begin{tabular}{|c|c|c|c|c|c|}
\hline \multirow[b]{2}{*}{ Patients } & & \multirow{2}{*}{$\begin{array}{l}\text { AChR reactive } \\
T \text { cells }\end{array}$} & \multicolumn{3}{|c|}{$\begin{array}{l}\text { Anti-AChR antibody } \\
\text { secreting cells }\end{array}$} \\
\hline & & & IgG & IgA & IgM \\
\hline \multirow{3}{*}{ MG group I } & Range & $0-12$ & $1-28$ & $0-9$ & $0-5$ \\
\hline & Mean (SD) & $4.0(4.1)$ & $9.7(7.9)$ & $3.5(3.1)$ & $1.5(1.6)$ \\
\hline & No exam & 16 & 14 & 14 & 13 \\
\hline \multirow[t]{4}{*}{ MG group II } & Range & $0-5$ & $0-13$ & $0-4$ & $0-1$ \\
\hline & Mean (SD) & $1.7(1.5)$ & $4.6(3.6)$ & $0.9(1.2)$ & $0.1(0.4)$ \\
\hline & No exam & 14 & 14 & 14 & 14 \\
\hline & $P$ value & 0.05 & 0.05 & 0.001 & 0.001 \\
\hline
\end{tabular}

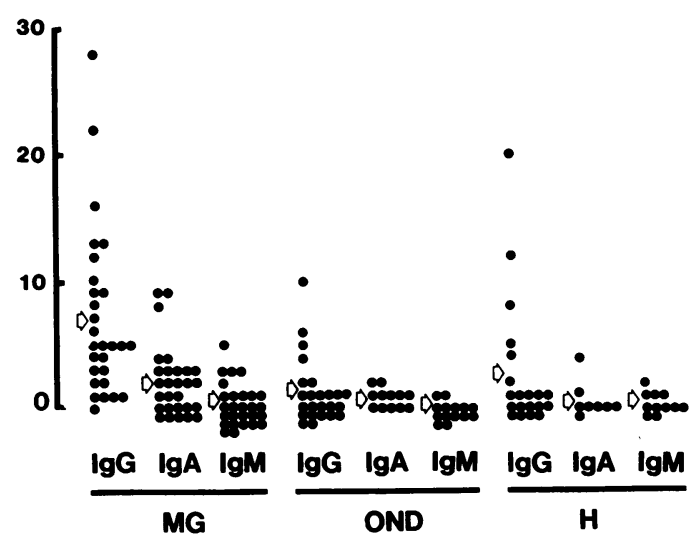

Figure 3. Anti-AChR receptor antibody secreting cells of IgG, IgA, and IgM isotypes per $10^{5}$ blood mononuclear cells from patients with myasthenia gravis $(M G)$ and other neurological diseases $(O N D)$, and healthy subjects $(H)$. Arrows denote mean values.

Our finding of AChR-reactive T cells in patients with OND is in accordance with previous observations by Newsom-Davis and his group of increased $T$ cell proliferation to $A C h R$ and to the AChR peptide $125-143$ in controls $(8,12)$. Whereas these authors detected AChR or peptide reactive T cells at similar frequencies and numbers in patients with $M G$ and controls, we observed that AChR-reactive $\mathrm{T}$ cells were more common and present at higher numbers in blood from patients with MG in comparison with patients with OND or healthy subjects. Also, the proliferative response to various $\mathrm{AChR}$ sequences has been shown to differ between MG patients and controls (27).

As control antigens in the T cell assay we used MBP and PLP, i.e., two myelin components of possible relevance in a putative immune pathogenesis of multiple sclerosis. Experimental autoimmune encephalomyelitis (EAE) can be induced by injection of MBP or PLP together with Freund's complete adjuvant (28-30), and represents to a certain extent an experimental model of multiple sclerosis. With the same $T$ cell immunospot assay as used in the present study, we have documented that patients with multiple sclerosis have high numbers of MBP- and PLP-reactive T cells in peripheral blood and especially in cerebrospinal fluid, i.e., in the compartment in the immediate vicinity of the target for a possible immune attack (16). We have also observed that MBP- and PLP-reactive T cells are not specific for multiple sclerosis but may occur in

Table IV. Number of IgA- and IgM-secreting Cells per $10^{5}$ Mononuclear Cells from Peripheral Blood from Patients with MG, OND, and Healthy Controls

\begin{tabular}{lllll}
\hline Patients & & IgG & \multicolumn{1}{c}{ IgA } & IgM \\
\hline MG & Range & $0-160$ & $1-210$ & $0-48$ \\
& Mean (SD) & $33(30)$ & $68(60)$ & $10(12)$ \\
& No pos/no exam & $27 / 28$ & $28 / 28$ & $22 / 27$ \\
OND & Range & $2-40$ & $1-169$ & $1-90$ \\
& Mean (SD) & $17(12)$ & $61(44)$ & $18(21)$ \\
& No pos/no exam & $18 / 23$ & $23 / 23$ & $23 / 23$ \\
Healthy & Range & $0-32$ & $10-152$ & $1-60$ \\
& Mean (SD) & $11(11)$ & $58(43)$ & $16(17)$ \\
& No pos/no exam & $17 / 20$ & $20 / 20$ & $20 / 20$ \\
\hline
\end{tabular}


other neurological diseases as well, but at lower frequencies and numbers. Our patients with MG had also MBP- or PLP-reactive $T$ cells in peripheral blood, though at frequencies and numbers which were similar to those which we observed in patients with OND and healthy controls. This T cell reactivity to MBP and PLP might reflect effectively controlled "normal" autoreactivity (31) whereas, in multiple sclerosis, the high numbers of MBP- and PLP-reactive T cells might have importance for a proposed immunopathogenesis, alternatively represent a consequence of myelin breakdown. Similarly, it remains to be proven whether the frequent occurrence of high numbers of AChR-reactive T cells in MG are involved in an assumed immunopathogenesis of the disease or reflect a phenomenon secondary to tissue destruction, or both.

IFN- $\gamma$ is a cytokine with multiple immunoregulatory effects, including the induction of class I and II MHC gene expression, macrophage activation and $\mathrm{T}$ cell homing. Perturbated secretion of IFN- $\gamma$ locally at AChRs by AChR-reactive T cells could be of importance in the pathogenesis of MG.

Utilizing the principle of detection of antibody secretion by individual cells, we have also demonstrated that practically every patient with MG has a $B$ cell response directed against the AChR. This involves predominantly IgG antibodies, but IgA and IgM antibodies as well. Anti-AChR antibodies of the IgM isotype have previously been reported in $\mathrm{MG}(32,33)$, whereas an IgA antibody response to $\mathrm{AChR}$ has to our knowledge not previously been demonstrated. The combined presence of AChR specific $T$ and $B$ cells is compatible with $T$ cell driven $B$ cell response in $\mathrm{MG}$.

Anti-AChR antibody secreting cells were present not only in MG but also in the two control groups, although at lower frequencies and numbers. Even though anti-AChR antibodies are generally considered to have pathogenetic relevance in MG, a number of inconsistencies have been described which question the association between anti-AChR antibodies and MG. High antibody levels may thus be demonstrated in MG patients in remission (34). Newborns to mothers with MG may have no signs of MG despite high levels of such antibodies (35). Different diseases such as epilepsy with IgA deficiency (36), primary biliary cirrhosis (37), and monoclonal gammopathies (38) may be accompanied by anti-AChR antibodies without signs of MG. A pair of identical 47-yr-old twins has been described, one of them with MG and the other with high levels of anti-AChR antibodies but no clinical signs of MG (39). It could be that anti-AChR antibodies are included in the broad repertoire of natural antibodies and that an abnormal proliferation of anti-AChR antibody secreting B cell and plasma cell clones, due to a mechanism which remains obscure, is responsible for destruction of AChR in MG. Alternatively, the high production of anti-AChR antibodies found in MG could represent an immune response secondary to AChR breakdown. Both possibilities are not mutually exclusive.

Our findings of higher numbers of AChR-reactive T and B cells in thymectomized MG patients could be a consequence of the influence on suppressor functions which have been attributed to the thymus (40). However, effects due to differences between thymectomized versus nonoperated patients in type and duration of other forms of immunomodulative measures are not excluded.

In conclusion, we have documented presence of AChRreactive $T$ cells and cells secreting anti-AChR antibodies in most patients with MG. We also observed a strong correlation between $B$ and $T$ cell responses to $A C h R$ in the MG patient material. AChR-reactive T and B cells are not specific for MG, but they are detected more frequently in blood from patients with MG, where they are found at higher numbers compared with patients with OND and healthy subjects. Adoption of the immunospot assay should facilitate identification of possible immunodominant epitopes which could be active in the immunopathogenesis of MG in the individual patient, and thereby constitute the basis for individually focused immunotherapy.

\section{Acknowledgments}

We are indebted to Dr. Georg Matell, Södersjukhuset, Stockholm, for permission to include his patients in this study, and to Ms. Yvonne Nilsson for excellent secretarial assistance.

This work was supported by grants from the Swedish Medical Research Council, the Swedish Multiple Sclerosis Society (NHR), and Karolinska Institutet research funds.

\section{References}

1. Almon, R. R., C. G. Andrew, and S. H. Appel. 1974. Serum globulin in myasthenia gravis: inhibition of $\alpha$-bungarotoxin binding to acetylcholine receptors. Science (Wash. DC). 186:55-57.

2. Vincent, A., and J. Newsom-Davis. 1980. Anti-acetylcholine receptor antibodies. J. Neurol. Neurosurg. Psychiatry. 43:590-600.

3. Toyka, K. V., D. B. Drachman, and D. E. Griffin. 1977. Myasthenia gravis: study of humoral immune mechanisms by passive transfer to mice. $N$. Engl. J. Med. 296:125-131.

4. Engel, A. G. 1980. Morphologic and immunopathologic findings in myasthenia gravis and in congenital myasthenia syndromes. J. Neurol. Neurosurg. Psychiatry. 43:577-589.

5. Lindström, J. 1985. Immunobiology of myasthenia gravis, experimental autoimmune myasthenia gravis and Lambert-Eaton syndrome. Annu. Rev. Immunol. 3:109-131.

6. Tzartos, S. J., A. Kokla, S. L. Walgrave, and B. M. Conti-Tronconi. 1988. Localization of the main immunogenic region of human muscle acetylcholine receptor to residues 67-76 of the $\alpha$-subunit. Proc. Natl. Acad. Sci. USA. 85:28992903.

7. Lennon, V. A., and G. E. Griesmann. 1989. Evidence against acetylcholine receptor having a main immunogenic region as target for autoantibodies in myasthenia gravis. Neurology. 39:1069-1076.

8. Newsom-Davis, J., G. Harcourt, N. Sommer, D. Beeson, N. Willcox, and J. B. Rothbard. 1989. T-cell reactivity in myasthenia gravis. J. Autoimmun. 2(Suppl.): 101-108.

9. Hohlfeld, R., K. V. Toyka, K. Heininger, H. Grosse-Wilde, and I. Kalies. 1984. Autoimmune human $T$ lymphocytes specific for acetylcholine receptor. Nature (Lond.). 310:244-246.

10. Hohlfeld, R., K. V. Toyka, S. J. Tzartos, W. Carson, and B. M. ContiTronconi. 1987. Human $\mathrm{T}$ helper lymphocytes in myasthenia gravis recognize the nicotinic receptor alpha subunit. Proc. Natl. Acad. Sci. USA. 84:5379-5383.

11. Tami, J., O. Urso, and K. A. Krolick. 1987. T cell hybridomas reactive with acetylcholine receptor and its subunits. $J$. Immunol. 138:732-738.

12. Harcourt, G. C., N. Sommer, J. Rothbard, H. N. A. Willcox, and J. Newsom-Davis. 1988. A juxta-membrane epitope on the human acetylcholine receptor recognized by $\mathrm{T}$ cells in myasthenia gravis. J. Clin. Invest. 82:12951300.

13. Lennon, V. A., D. J. McCormick, E. H. Lambert, G. E. Griesmann, and M. Z. Atassi. 1985. Region of peptide 125-147 of acetylcholine receptor $\alpha$-subunit is exposed at neuromuscular junction and induces experimental autoimmune myasthenia gravis, T-cell immunity, and modulating autoantibodies. Proc. Natl. Acad. Sci. USA. 82:8805-8809.

14. Hecht, T. T., D. L. Longo, and L. A. Matis. 1983. The relationship between immune interferon production and proliferation in antigen-specific. MHC-restricted T cell lines and clones. J. Immunol. 131:1049-1055.

15. Kabilan, L., G. Andersson, F. Lolli, H.-P. Ekre, T. Olsson, and M. TroyeBlomberg. 1990. Detection of intracellular expression and secretion of interferongamma at the single-cell level after activation of human $\mathrm{T}$ cells with tetanus toxoid in vitro. Eur. J. Immunol. 20:1085-1089.

16. Olsson, T., W. Z. Wang, B. Höjeberg, V. Kostulas, Y.-P. Jiang, G. Andersson, H.-P. Ekre, and H. Link. 1990. Autoreactive T lymphocytes in multiple sclerosis determined by antigen induced secretion of interferon-gamma. J. Clin. Invest. 86:981-985.

17. Czerkinsky, C. C., L. A. Nilsson, and H. Nygren. 1983. A solid-phase 
enzyme-linked immunospot (ELISPOT) assay for enumeration of specific antibody secreting cells. J. Immunol. Methods. 65:109-121.

18. Sedgewick, J. D., and P.-G. Holt. 1983. A solid-phase immunoenzymatic technique for the enumeration of specific antibody secreting cells. J. Immunol. Methods. 57:301-304.

19. Aharounov, A., R. Tarrab-Hazdai, I. Silman, and S. Fuchs. 1977. Immunochemical studies on acetylcholine receptor from Torpedo californica. Immunochemistry. 14:129-137.

20. Deibler, G. E., R. E. Martensson, and M. V. Kies. 1972. Lange scale preparation of myelin basic protein from central nervous tissue of several mammalian species. Prep. Biochem. 2:139-165.

21. Lees, M. B. 1982. Proteolipids. Scand. J. Immunol. 15:147-169.

22. Czerkinsky, C. C., G. Andersson, H.-P. Ekre, L.-Ả. Nilsson, L. Klareskog, and Ö. Ouchterlony. 1988. Reverse EISPOT assay for clonal analysis of cytokine production. I. Enumeration of gamma-interferon-secreting cells. J. Immunol. Methods. 110:29-36.

23. Andersson, G., H.-P. Ekre, G. Ahn, and P. Perlmann. 1989. Monoclonal IFN- $\gamma$. Adaption for determinations in human serum and plasma. J. Immunol. Methods. 125:89-96.

24. Olsson, T., V. Kostulas, and H. Link. 1984. Improved detection of oligoclonal IgG in cerebrospinal fluid by agarose isoelectric focusing, double-antibody peroxidase and avidin-biotin amplification. Clin. Chem. 30:1246-1249.

25. Baig, S., T. Olsson, and H. Link. 1989. Neuroborreliosis: predominance of Borrelia burgdorferi specific B cells in cerebrospinal fluid in neuroborreliosis. Lancet. ii:71-74.

26. Zachau, A., K. Strigård, S. Baig B. Höjeberg and T. Olsson. 1989. Distribution of plasma cells secreting antibodies against nervous tissue antigens during experimental allergic encephalomyelitis enumerated by nitrocellulose immunospot assay. J. Neurol. Sci. 91:323-336.

27. Brocke, S., C. Brautbar, L. Steinman, O. Abramsky, J. Rothbard, D. Neumann, S. Fuchs, and E. Mozes. 1988. In vitro proliferative responses and antibody titres specific to human acetylcholine receptor synthetic peptides in patients with myasthenia gravis and relation to HLA class II genes. J. Clin. Invest. 82:1894-1900.

28. Waksman, B. H., H. Porter, M. D. Lees, R. D. Adams, and J. Flach. 1954.
A study of the chemical nature of components of bovine white matter effective in producing allergic encephalomyelitis in the rabbit. J. Exp. Med. 100:451-471.

29. Burns, J., A. Rosenzweig, B. Zweiman, and R. P. Lisak. 1983. Isolation of myelin basic protein-reactive T-cell lines from hormal human blood. Cell. Immunol. 81:435-440.

30. Satoh, J., K. Sakai, M. Endoh, F. Koike, T. Kunishita, T. Namikawa, T. Yamamura, and T. Tabira. 1987. Experimental allergic encephalomyelitis mediated by murine encephlitogenic $T$ cell lines specific for myelin proteolipid apoprotein. J. Immunol. 138:179-184.

31. Zauderer, M. 1989. Origin and significance of autoreactive T cells. Adv. Immunol. 45:417-437.

32. Lefvert, A. K., K. Bergström, G. Matell, P. O. Osterman, and R. Pirskanen. 1978. Determination of acetylcholine receptor antibody in myasthenia gravis: clinical usefulness and pathogenetic implications. $J$. Neurol. Neurosurg. Psychiatry. 41:394-403.

33. Tindall, R. S. A. 1980. Humoral immunity in myasthenia gravis: effect of steroids and thymectomy. Neurology. 30:554-557.

34. Oosterhuis, H. 1977. The natural course of myasthenia gravis: a long term followup study. J. Neurol. Neurosurg. Psychiatry. 52:1121-1127.

35. Keesey, J., J. Lindstrom, H. Cokely, and C. Herrmann. 1977. Anti-acetylcholine receptor antibody in neonatal myasthenia gravis. N. Engl. J. Med. 296:55.

36. Fontana, A., B. W. Fulpins, and S. Cuénoud. 1978. Antikörper gegen nicotinartige acetylcholinrezeptoren des zentralnervensystems und der muskulatur bei epileptikern mit IgA-mangel. Schweiz. Med. Wochenschr. 108:13071310.

37. Sundewall, A. C., A. K. Lefvert, and R. Olsson. 1985. Anti-acetylcholine receptor antibodies in primary biliary cirrhosis. Acta Med. Scand. 217:519-525.

38. Eng, H., A. K. Lefvert, H. Mellstedt, and A. Österborg. 1987. Human monoclonal immunoglobulins that bind the human acetylcholine receptor. Eur. J. Immunol. 17:1867-1869.

39. Lefvert, A. K., R. Pirskanen, H. Eng, A.-C. Sundewall, and E. Svanborg. 1989. B cell and autoantibody repertoire in a pair of monozygotic twins discordant for myasthenia gravis. Clin. Immunol. Immunopathol. 53:161-170.

40. Waksman, B. H. 1977. Tolerance, the thymus and suppressor T cells. Clin. Exp. Immunol. 28:363-374. 